\title{
Entre la vida y la muerte. Testamentos de don Gabriel y doña Lucrecia Fernández Guarachi (Jesús de Machaca, Pacajes, siglo XVII)
}

Between life and death. Testaments by don Gabriel and doña Lucrecia

Fernández Guarachi (Jesús de Machaca, Pacajes, 17th Century)

\section{Ariel J. Morrone}

\section{(2) OpenEdition}

\section{Journals}

\section{Edición electrónica}

URL: http://journals.openedition.org/corpusarchivos/385

DOI: $10.4000 /$ corpusarchivos.385

ISSN: 1853-8037

Editor

Diego Escolar

\section{Referencia electrónica}

Ariel J. Morrone, « Entre la vida y la muerte. Testamentos de don Gabriel y doña Lucrecia Fernández

Guarachi (Jesús de Machaca, Pacajes, siglo XVII) », Corpus [En línea], Vol 3, No 1 | 2013, Publicado el

15 junio 2013, consultado el 07 mayo 2019. URL : http://journals.openedition.org/corpusarchivos/385 ; DOI : 10.4000/corpusarchivos.385

Este documento fue generado automáticamente el 7 mayo 2019.

Licencia Creative Commons: Atribución-NoComercial 2.5 Argentina (CC BY-NC 2.5 AR) 


\title{
Entre la vida y la muerte. Testamentos de don Gabriel y doña Lucrecia Fernández Guarachi (Jesús de Machaca, Pacajes, siglo XVII)
}

\author{
Between life and death. Testaments by don Gabriel and doña Lucrecia \\ Fernández Guarachi (Jesús de Machaca, Pacajes, 17th Century)
}

Ariel J. Morrone

\section{NOTA DEL EDITOR}

Fecha de recepción del original: 10-04-2013

Fecha de aceptación para publicación: 14-05-2013

\section{Textos y contextos}

1 En febrero de 1978 se publicó en La Paz el primer número de Avances. Revista Boliviana de Estudios Históricos y Sociales. La misma constituía una intervención de un grupo de intelectuales interesados en esclarecer los procesos históricos atravesados por la sociedad boliviana, con una fuerte impronta política. Su comité editorial proponía, ya desde la presentación, auspiciar "el verdadero debate y trabajo de autorreflexión que nos permitirá desarrollar la visión histórica y existencial tan necesaria para el porvenir" (1978, p. 6). Los trabajos publicados, en tanto "avances de investigación", tenían como objetivo indagar en el pasado colonial para identificar claves analíticas que dieran sentido a procesos sociales más recientes. Así, aquel primer número de Avances incluyó un dossier titulado "Caciques, comunidad y Estado", abordando el proceso colonial a partir de aquella figura que Nicolás Sánchez Albornoz (1978: 99-107) había calificado como "pieza 
maestra" del dominio español en la región andina: las autoridades étnicas, los kuraka o mallku, "caciques" en general.

Avances abrió su agenda de reflexiones con un artículo a cargo de la socióloga e historiadora boliviana Silvia Rivera Cusicanqui. La autora discutía los argumentos de Nathan Wachtel (1973), según el cual la conquista y posterior colonización de las sociedades andinas había producido un impacto desestructurante en sus pautas sociales de reproducción, alterando los patrones básicos de organización parental (asociados a la reciprocidad). Los líderes étnicos, entonces, habrían desvirtuado su autoridad hacia un "despotismo" desmedido. También criticaba los planteos de Maurice Godelier (1974), quien afirmaba que la imposición de un sistema de cargos durante el período colonial devino en un borramiento de las diferencias sociales al interior de las comunidades.

En este estado de la discusión, Rivera Cusicanqui ofrece un análisis pormenorizado del testamento de don Gabriel Fernández Guarachi, cacique de pueblo de Jesús de Machaca (corregimiento de Pacajes, actual provincia Ingavi del departamento de La Paz) durante gran parte del siglo XVII ${ }^{1}$. La autora logró mostrar cómo, a partir del manejo de los recursos colectivos (fundamentalmente ganado y mano de obra), el cacique garantizó las condiciones de reproducción de los ayllu (agrupaciones parentales de base) al tiempo que fue más que exitoso participando en los mercados surandinos. Lejos del "despotismo" planteado por Wachtel, Rivera Cusicanqui muestra las estrategias articuladas por Fernández Guarachi en beneficio de los suyos. Así, el éxito comercial en los mercados coloniales hizo de don Gabriel y los sucesivos caciques Fernández Guarachi, uno de los linajes nativos de mayor renombre, poder e influencia en los Andes meridionales del siglo XVII y las primeras décadas del siglo XVIII (Urioste de Aguirre, 1978; Choque Canqui, 1983, 1993, 2003; Gisbert, 1992; Morrone, 2010a, 2010b).

El carácter ambivalente de los caciques coloniales, su particpación en los mercados coloniales como activos agentes del intercambio de bienes en el espacio colonial y su rol de intermediación política entre los ayllu y el poder colonial fueron tópicos que definieron los carriles de la investigación etnohistórica desde entonces (Stern, 1986 [1982], Saignes, 1984, 1986, 1987; Harris, Larson y Tandeter, 1987; Pease G. Y., 1992; Platt, Bouysse-Cassagne y Harris, 2006). De este modo, las prácticas de los caciques coloniales desde su posición como "bisagras entre dos mundos" ha devenido en uno de las tópicos centrales para las siguientes generaciones de estudiosos del mundo andino. La documentación producida por la adminsitración colonial (expedientes judiciales, padrones de indios, pleitos por tierras y sucesiones, protocolos notariales, entre otros), principales protagonistas de la renovación de la disciplina etnohistórica, vuelve a ser revisada a la luz de nuevas preguntas (Lorandi y del Río, 1992). Pero también ocurre que nuevos documentos salen a la luz; tal es el caso que presentamos a continuación.

\section{Encajando las piezas documentales}

Como muchas veces ocurre en la historiografía, los nuevos proyectos de investigación generan nuevas campañas de relevamiento documental, las cuales bien pueden redundar en el hallazgo de nuevas fuentes o en la problematización de fuentes ya trabajadas. Durante una estancia de relevamiento en el Archivo de La Paz en junio de 2009, dimos con un expediente de 1745 en el que don Sebastián Cosme, principal y segunda persona de Jesús de Machaca, acompañado por otros principales del pueblo, denunciaba ante el maestre de campo don Juan Antonio de Obaya, juez comisionado por la Audiencia de 
Charcas, a don Tomás Fernández Guarachi, miembro de la familia cacical, por haberse apropiado ilegítimamente de la estancia de San Pedro de Pocoraya y Chixcha².

Emplazada a unos $20 \mathrm{~km}$ al sudeste del pueblo, sobre la orilla izquierda del río Desaguadero y lindando con las tierras del pueblo de Caquiaviri, la estancia de San Pedro de Pocoraya y Chixcha presentaba óptimas condiciones de fertilidad para los cultivos de altura (tubérculos y legumbres) y el pastoreo de ganado. El alegato de don Sebastián Cosme se remontaba a mediados del siglo XVII, más precisamente a 1647 , fecha en que don Gabriel Fernández Guarachi, a la sazón cacique del pueblo, había adquirido la estancia durante los procesos de visita y composición de tierras llevadas adelante por el gobierno colonial. El cacique había logrado, a través de una significativa erogación monetaria, asegurar la posesión de catorce estancias y consolidar el territorio de los ayllu del pueblo, limitando así la apropiación privada de la tierra (hacienda). La posesión de estas estancias sería confirmada posteriormente en 1659, durante la visita de tierras realizada por don Gerónimo Luis de Cabrera (Choque Canqui, 2003, pp. 209-215; Loza, 2003; Jurado, 2007).

7 Para mayor sustento de su caso, don Sebastián Cosme presentó entre los instrumentos probatorios un traslado del testamento de don Gabriel Fernández Guarachi, dado en Potosí el 10 de marzo de 1673. Se trata del mismo documento que el publicado en 1978 por Silvia Rivera Cusicanqui, con dos diferencias. En primer lugar, el traslado de 1745 incluye el primer folio (ausente en la edición de Rivera), que reproduce la estructura básica de los testamentos de la época: una introducción sacramental, la identificación del testador, la solicitud de asistencia e intercesión divina y una meditación sobre la muerte (Ramos, 2010, pp. 156-168). Si bien este primer folio está confeccionado en función de los formulismos típicos del registro, su incorporación al documento publicado en 1978 permite completar la pieza (Documento 1). Así, confirmamos la filiación del cacique y el nombre de sus padres, don Pedro Guarachi y doña María Casi (Choque, 2003, pp. 58-59).

La segunda diferencia es la inclusión de un codicilo, otorgado en Jesús de Machaca tres meses después del testamento, por el cual el cacique establecía la posesión de la estancia de San Pedro de Pocoraya y Chixcha a los ayllu del pueblo "por el amor que les tengo" (f. 21r), ampliando los términos de la cláusula correspondiente (Documento 2). En base a estas pruebas, don Sebastían Cosme denunciaba la apropiación y los malos tratos infligidos por don Tomás Fernández Guarachi, nombrado cacique interino por el corregidor.

Pero más aún: dado que don Gabriel había nombrado como sus herederas universales a sus dos únicas hijas legítimas, doña Lucrecia y doña María Fernández Guarachi, el expediente en cuestión también incorpora un traslado del segundo testamento de doña Lucrecia, dado en el asiento de minas de San Juan de Berenguela (términos del pueblo de Santiago de Machaca) el 4 de febrero de 1694 (Documento 3). Se trata, en realidad, de la ejecución del poder que doña Lucrecia otorgó a su (medio) hermano don Bonifacio Fernández Guarachi y al bachiller Miguel de Larrea y Mudarra, cura interino de la parroquia de Santa Cruz y San Sebastián de Cepita, para que modificaran a su criterio las cláusulas de su primer testamento, otorgado diez años antes. Incluimos este documento por su gran relevancia a la hora de ponderar el rol que ejerció doña Lucrecia en la distribución del patrimonio de su padre entre el conjunto de los hijos (legítimos y naturales) del cacique (Choque Canqui, 2003, pp. 90-103). 


\section{Posibles derivaciones}

10 El análisis de los testamentos de las elites nativas coloniales ha recibido importantes avances en los últimos años, tanto en el espacio novohispano (Ruz, 2002; Jiménez Abollado, 2008; Reyna Rubio, 2012) como en el andino (Abercrombie, 1998; Presta, 2002; Nowack, 2006; Ramos, 2010, pp. 155-205). A modo de balance, y para cerrar nuestro aporte, proponemos tres líneas de reflexión para futuras investigaciones:

11 3.1. Uno de los rasgos que caracterizaron el proceso de transformación de las autoridades nativas durante el período colonial fue la incorporación de pautas culturales propias del mundo hispánico. Entre ellas, señalaremos la lectoescritura en idioma castellano, la observancia de la religiosidad cristiana y la adopción de la cultura material hispánica (objetos de consumo diverso, vestimenta, caballos) que orotgaba un status superior en una sociedad donde lo importante no era tanto "ser" como "parecer" y "valer más" (Gisbert, 1992; Pease, 1992; Presta, 2000, pp. 25-30). Cabe destacar el interés de las autoridades nativas por protocolizar sus vínculos sociales, con el fin de consolidar sus redes personales y clientelares y dejar asentado por escrito cada instancia de su vida social. La adopción del método escriturario hispánico constituyó una herramienta clave en el establecimiento de nuevos criterios de legitimidad de los caciques andinos coloniales. $\mathrm{Si}$ en tiempos prehispánicos la memoria genealógica era eminentemente oral, la situación abierta por el dominio colonial implicó la incorporación de la escritura, sus soportes específicos y un nuevo conjunto de prácticas asociadas. En su calidad de escritura pública, los testamentos de los caciques coloniales constituyen verdaderas ventanas de acceso al conjunto de sus relaciones y redes personales y familiares, y si bien la voz del testador se halla mediada por notarios y escribanos, la intencionalidad manifiesta de cifrar y delinear una memoria genealógica da cuenta de una práctica de "apropiación del signo" (Chang Rodríguez, 1988). Más que pensar en una tensión entre oralidad y escritura, ambos registros bien podrían interactuar, toda vez que los testamentos se nutrían de la oralidad y se leían en alta voz, al tiempo que el registro oral se valía de la palabra escrita para autolegitimarse (Astvaldsson, 2000, pp. 102-104).

3.2. La sistematización del dominio colonial también implicó la puesta en juego de los criterios de legitimidad de las autoridades étnicas, quienes debieron redefinir alianzas para reposicionarse en el nuevo escenario político. Hacia fines del siglo XVI, y a partir de la implementación de las reformas toledanas, quedaron establecidos tres criterios básicos para acceder al cargo de "cacique principal y gobernador": cristiandad, heredabilidad y habilidad. Del mismo modo que las probanzas de méritos y servicios, los testamentos pueden ser leídos como un alegato autolegitimador por parte del testador. En una misma pieza escrita, el "buen cacique colonial" reafirmaba sus convicciones en la fe católica, propugnaba su observancia entre sus súbditos y su difusión a través de las disposiciones testamentarias (bajo la figura de la donatio pro anima), conjuraba cualquier atisbo de prácticas "idolátricas", establecía una (o más) línea(s) de ascendencia a través de la memoria genealógica, delimitaba su propio núcleo familiar al distribuir su patrimonio y se mostraba como diestro conocedor de los vericuetos del sistema colonial. En tanto género discursivo, los testamentos de los caciques andinos coloniales cristalizarían entonces como instrumentos de legitimación política, cuyos destinatarios incluían tanto los funcionarios y miembros del segmento dominante de la sociedad como sus propios súbditos al nivel de los ayllu. 
3.3. Finalmente, podemos conceptualizar los testamentos como una práctica tendiente a otorgar cierto sentido frente a la inevitabilidad de la muerte (Ramos, 2010, pp. 283-285). Si el fin de la vida humana constituye un acontecimiento inexorable, la meticulosa elaboración del testamento formaría parte del ritual puesto en acto para bregar con el cruce de la frontera entre la vida y la muerte. Reafirmarse en la doctrina católica, encomendar el alma a los santos, dar cuenta de los bienes habidos y particionarlos entre los herederos, declarar deudores y acreedores, en definitiva, realizar un balance de cuentas para ordenar todos los asuntos de la (presente) vida sería la condición para garantizar un tránsito exitoso a la próxima, como así también un recurso aliviador ante la irreversibilidad de la muerte.

\section{Normas de transcripción}

Para la transcripción del documento de 1745 se actualizaron las mayúsculas y minúsculas para facilitar la lectura. Las notaciones al margen se han señalado con negritas, dejando un espaciado mayor antes de comenzar el texto correspondiente. Las abreviaturas se han desplegado. Se han simplificado las reduplicaciones de letras. Se mantuvo la "y" con el valor vocálico según corresponda. Se han conservado algunos signos de puntuación propios del amanuense (=). Asimismo, hemos remecanografiado la transcipción realizada por Silvia Rivera Cusicanqui en 1978, manteniendo los mismos criterios de la edición original (a excepción de las letras reduplicadas, que fueron simplificadas). En ambos casos, las aclaraciones y/o agregados se consignaron entre corchetes, y las voces latinas se escribieron con letras itálicas.

\section{BIBLIOGRAFÍA}

Abercrombie, T. A. (1998). Tributes to bad conscience: charity, restitution, and inheritance in cacique and encomendero testaments of sixteenth-century Charcas. En S. Kellogg y M. Restall (eds.), Dead Giveaways. Indigenous Testaments of Colonial Mesoamerica and the Andes, (pp. 249-289). Salt Lake City: University of Utah Press.

Astvaldsson, A. (2000). Las Voces de los Wak'a. La Paz: CIPCA.

Chang Rodríguez, R. (1988). La Apropiación del Signo. Tres cronistas indígenas del Perú. Tempe: Arizona State University.

Choque Canqui, R. (1983). El papel de los capitanes de indios de la provincia de Pacajes 'en el entero de la mita' de Potosí. Revista Andina, 1, 1, 117-125.

Choque Canqui, R. (1993). Sociedad y Economía Colonial en el Sur Andino. La Paz: Hisbol.

Choque Canqui, R. (2003). Jesús de Machaqa: La marka rebelde. 1. Cinco siglos de historia. La Paz: Plural-CIPCA. 
Gisbert, T. (1992). Los curacas del Collao y la conformaión de la cultura mestiza andina. En H. Tomoeda y L. Millones (Eds.), 500 Años de Mestizaje en los Andes, (pp. 52-102). Senri Ethnological Studies 33, Osaka: National Museum of Ethnology.

Godelier, M. (1974). El concepto de 'formación económica y social': el ejemplo de los incas. En Economía, Fetichismo y Religión en las Sociedades Primitivas, (pp. 176-184). Madrid: Siglo XXI.

Harris, O., Larson, B. y Tandeter, E. (Comps.) (1987). La Participación Indígena en los Mercados Surandinos. Estrategias y reproducción social, siglos XVI-XX. La Paz: CERES.

Jiménez Abollado, F. L. (2008). Don Diego Luis Moctezuma, nieto de Hueytlatoani, padre de conde: un noble indígena entre dos mundos. Anuario de Estudios Americanos, 65 (1), 49-70.

Jurado, M. C. (2007). La legalización de la memoria: una mirada a las composiciones de tierras norpotosinas a fines del siglo XVI. Ponencia presentada en las XI Jornadas Interescuelas/ Departamentos de Historia, Tucumán, 19 al 21 de septiembre.

Lorandi, A. M. y del Río, M. (1992). La Etnohistoria. Etnogénesis y transformaciones sociales andinas. Buenos Aires: CEAL.

Loza, C. B. (2003). Norma y práctica del reordenamiento jurídico territorial de Laricaxa (La Paz, 1656-1660). Historia y Cultura, 28-29, 39-75.

Morrone, A. J. (2010a). Legitimidad, genealogía y memoria en los Andes meridionales: los Fernández Guarachi de Jesús de Machaca (Pacajes, siglos XVI-XVII). Memoria Americana. Cuadernos de Etnohistoria, 18, 2, 211-237.

Morrone, A. J, (2010b). Clero rural y liderazgo étnico en el corregimiento de Pacajes: la antigua iglesia de Jesús de Machaca (siglo XVII). Anuario de Estudios Bolivianos, Archivísticos y Bibliográficos, $16,445-475$.

Nowack, K. (2006). ‘Como cristiano que soy': testamentos de la elite indígena en el Perú del siglo XVI. Indiana, 26, 51-77.

Pease G. Y., F. (1992). Curacas, Reciprocidad y Riqueza. Lima: PCUP.

Platt, T., Bouysse-Cassagne, T. y Harris, O. (2006). Qaraqara-Charka. Mallku, Inka y Rey en la provincia de Charcas (siglos XV-XVII). Historia antropológica de una confederación aymara. La Paz: IFEA-Plural.

Presta, A. M. (2000). Encomienda, Familia y Negocios en Charcas Colonial. Los encomenderos de La Plata, 1550-1600. Lima: IEP-BCRP.

Presta, A. M. (2002). De testamentos, iniquidades de género, mentiras y privilegios: doña Isabel Sisa contra su marido, el cacique de Santiago de Curi. En J. Flores Espinoza y R. Varón Gabai (Eds.), El Hombre y los Andes. Homenaje a Franklin Pease G. Y., (tomo II, pp. 817-829). Lima: PCUP. Ramos, G. (2010). Muerte y Conversión en los Andes. Lima y Cuzco, 1532-1670. Lima: IEP-IFEA.

Reyna Rubio, M. (2012). Los testamentos como fuentes para el estudio de la cultura material de los indios en los valles de Puebla-Tlaxcala y Toluca (s. XVI y XVII). Temas Americanistas, 29, 179-199.

Rivera Cusicanqui, S. (1978). El mallku y la sociedad colonial en el siglo XVII: el caso de Jesús de Machaca. Avances, 1, 7-27.

Ruz, M. H. (2002). De antepasados y herederos: testamentos mayas coloniales. Alteridades, 12, 24, 7-32. 
Saignes, T. (1984). Las etnias de Charcas frente al sistema colonial (Siglo XVII). Ausentismo y fugas en el debate sobre la mano de obra indígena, 1595-1665. Jahrbuch fur Geschichte von Staat, Wirtschaft und Gesselschaft Lateinamerikas, XXI, 27-75.

Saignes, T. (1986). En Busca del Poblamiento Étnico de los Andes Bolivianos (Siglos XV y XVI). La Paz: MUSEF.

Saignes, T. (1987). De la borrachera al retrato: los caciques andinos entre dos legitimidades (Charcas). Revista Andina, 5, 1, 130-170.

Sánchez Albornoz, N. (1978). Indios y Tributos en el Alto Perú. Lima: IEP.

Stern, S. J. (1986 [1982]). Los Pueblos Indígenas del Perú y el Desafío de la Conquista Española. Huamanga hasta 1640. Madrid: Alianza.

Urioste de Aguirre, M. (1978). Los caciques Guarache. Estudios Bolivianos en Homenaje a Gunnar Mendoza L., 131-140.

Wachtel, N. (1973). La desestructuración económica y social del mundo andino. En Sociedad e Ideología, (pp. 73-92). Lima: IEP.

\section{ANEXOS}

\section{Transcripciones paleográficas}

\section{Documento 1. Testamento de don Gabriel Fernández Guarachi, cacique principal de Jesús de Machaca. Potosí, 10 de marzo de 1673. Archivo de La Paz, Juzgado de Pacajes, Caja 11 (1730-1749): "Espediente seguido sobre las tierras de la pirca de Chicchas canton Jesus de Machaca", folios 18r-22r.}

[18r] En el nombre de Dios Todo Poderoso con cuia Gracia todas las cosas tienen buen principio, loable medio y dichoso fin, sea notorio a los que esta carta y escriptura de testamento vieren como yo don Gabriel Fernandes Guarache natural y cacique principal y governador de el pueblo de Jesus de Machaca en la provincia de Pacaxes hijo lexitimo de don Pedro Guarache cacique principal y governador que asimesmo fue del dicho pueblo y de doña Maria Casi su lexitima muger ambos difuntos estando emfermo de la emfermedad que Dios a sido servido de darme y en mi entero juisio y entendimiento tal qual Dios fue servido de darme y por ser cosa natural la muerte y no saverse el dia y su ora de ella y que no me coxa del todo desdichado es mi voluntad haser y ordenar las cosas que ymportan a mi alma y poniendolas en efecto y creiendo como firmemente creo y comfieso en el misterio de la Santisima Trinidad Padre Hijo y Espiritu Santo tres personas distintas y un solo Dios verdadero en unica esencia y en todo aquello que cree y comfiesa nuestra Santa Madre Yglesia Catholica Romana, devajo de cuia fe y creencia he vivdo hasta oy y protesto vivir en lo restante de mi vida hasta mi fallecimiento con protestacion que buelbo a haser que si por la gravedad de la emfermedad que adolesco a ylucion del Demonio nuestro capital enemigo o por otra cualquiera causa o accidente o otra cosa dijere o diere a entender al contrario no sea en ci ninguna ni de ningun valor ni efecto y para / [18v] todo ymboco con todo afecto y reverencia por mi abogada e yntersesora a la Purisima Virgen 
Santa Maria madre del Vervo Eterno y a los gloriosos apostoles San Pedro y San Pablo y al arcangel San Gabriel y a todos los demas santos y santas de la corte de el cielo para que sean medianeros con Su Divina Magestad que perdone mis culpas y pecados y deseando como deseo poner mi alma en carrera de salvacion y devajo de la creencia referida y de todo aquello que deve creer y confesar por donde nuestra Santa Madre Yglesia Romana hago y hordeno mi testamento ultima y postrimera voluntad en la forma y manera siguientes

Primeramente encomiendo mi alma a Dios Nuestro Señor que se crio y redimio con su presiosa sangre pacion y muerte y el cuerpo a la tierra de donde fue formado

Iten mando que quando Dios fuere servido de llevarme de esta presente vida sea mi cuerpo enterrado en el combento del Señor San Francisco de esta villa en la parte y lugar y ciudad donde muriere en la boveda de la capilla maior y mi cuerpo sea revestido con el avito de Señor San Francisco y se pague por el / [2r [a la limosna acostumbrada

Iten quiero y es mi voluntad que despues del dicho dia de mi entierro se diga un novenario de misas cantadas por los religiosos de nuestro Padre San Francisco sin vigilia que asi es mi voluntad y se pague la limosna acostumbrada

Iten quiero y es mi voluntad que toda la sera gruesa y menuda que se hubiese de poner y servir en mi entierro y en las misas referidas sea a orden y disposision de mis alvaseas y se pague el precio de ella de mis vienes

Iten mando se den al cura y beneficiado del pueblo de Jesus de Machaca que es o lo fuere en tiempo de mi fallecimiento ochenta pesos para que me digan veinte misas cantadas en esta forma las diez por las almas de mis visabuelos, abuelos, padre y madre y las otras diez por mi alma

Iten mando que de los dichos mis / [2v] vienes se den de limosna cient pesos para misas al padre guardian que es o fuere del combento de nuestro padre San Francisco de la ciudad de La Paz para que con toda brevedad se digan por mi alma cient misas por los religiosos del dicho combento

Iten mando que de los dichos mis vienes se den de limosna para redempcion de captibos cinquenta pesos corrientes que se entregaran al padre comendador de la ciudad de La Paz o a la persona a cuyo cargo estubiere el recogimiento de las dichas limosnas

Iten mando que de los dichos mis bienes se den de limosna a los santos lugares de Jerusalem cinquenta pesos corrientes que se entregaran al padre que pide la dicha limosna o a la persona que tubiere a su cargo el recojimiento de dichas limosnas que asi es mi voluntad

Iten mando a las mandas forzosas y acostumbradas a ocho pesos con que las / [3r] aparto de mis vienes

Iten quiero y es mi voluntad que se erija y edifique templo e iglecia en mi pueblo de Jesus de Machaca por haver muchos años que hize promesa de haserla a su Divina Magestad porque la que esto oy de presente se esta cayendo y amenasando ruina para cuio efecto tengo dedicados veinte mil pesos que los dies y ocho mil estan en casa y en poder de doña Lucrecia Guarache mi hija y los dos mil al cumplimiento de dicha cantidad estan en poder de don Pedro Fernandes Guarache que los a de poner con cuia cantidad se han de comprar cuatro chacaras llamadas Huchuicanqui.- Yamora.- Villcapucio.- Ychillcani.- para que con las cosechas y frutos que hubiere de ellas se baya poniendo en obra y edificando la dicha 
Iglecia lebantandose paredes y enmaderando y cubriendo y hasien / [3v] do campanario o Torre con sus campanas y los aderentes nesesarios para el adorno de ella, y al casique principal y governador de el dicho pueblo de Jesus de Machaca le encargo y pido tenga particular cuidado en acudir con puntualidad a esta fabrica para que Dios Nuestro Señor y su madre santisima tengan casa desente, pues la vigilancia y cuidadoso afecto que en esto pusiere le servira de merito para alcansar el devido premio y perdon de sus pecados, demas de lo cual le encargo y mando a don Diego Guarache mi hijo que baya a ver los linderos y terminos y mojones de las dichas chacaras que asi se an de comprar y en su conformidad se hara venta de ellas

Iten mando y es mi voluntad que si Dios fuere servido de que la dicha Iglecia se acave perfectamente y que tenga todos los adornos y aderentes nesesarios de casullas, albas, frontales y hor / [4r] namentos forsosos las dichas quatro haciendas y chacaras se distribuyan con el orden y en la forma siguiente

La una hacienda y chacara desde luego aplico los frutos y cosechas de ella para los hornamentos de la dicha iglecia, retablo, lienzos y colgaduras, lampara. - - Y la otra para el sustento de recogidas que se a de haser casa de recogimiento en el dicho mi pueblo. - La otra para el sustento de un Hospital que se a de haser para los indios pobres del dicho mi pueblo. - - y la última y quarta si se alcansare a comprar demas de las tres con la cantidad de los dichos veinte mi pesos aplico los frutos de ella hasta en cantidad de doscientos y cinquenta pesos a un maestro de escuela para que enseñe a leer, escrebir y la Doctrina Christiana a los muchachos y muchachas de el dicho pueblo

Iten declaro que yo fui casado / [4v] y velado segun orden de nuestra Santa Madre Iglecia con doña Maria Hachama natural del dicho mi pueblo que ya es difunta y durante el dicho matrimonio que fueron seis años tubimos algunos hijos y solo quedaron vivos doña Lucrecia y doña Maria Fernandez Guarache declarolas por tales mis hijas legitimas Iten declaro que quando case con la dicha doña Maria Hachama no trajo a mi poder vienes algunos ni tan solamente una obeja declarolo asi para que conste

Iten declaro que despues que enviude e tenido cinco hijos varones naturales y quatro mugeres que son.- Don Diego. Don Bonifacio. Juan.- Ignacio.- Francisco Guarache.- Doña Maria Cusi.- Magdalena Guarache.- Juana Guarache y otros dos hijos de Maria Orcoma.declarolos por mis hijos naturales

Iten declaro por mis vienes rayces / [5r] la chacara de Hancocaua y Copachullpa que compre de Pedro Melchor Cubarrubias en el valle de Cavari jurisdiccion de Sicasica como consta de la escriptura que me otorgo de venta y de los demas titulos y confirmaciones de ella

Iten otra chacara nombrada Quiñaspo y Cachacacha que la huve y compre de don Francisco Antonio de la Masueca Alvarado Jues Visitador de tierras por realengas de Su Magestad en el valle de Cavari de que tengo titulos y confirmaciones del real gobierno.Iten en el dicho valle de pueblo de Capiñata otra chacara nombrada Haasa que la compré de doña Beatriz de Gusman y Flores con otra que esta pegada a esta llamada Porotani que son chacaras de pan llevar

Iten en el dicho valle de Cavari otra chacara y haziendas de pan llebar llamadas Corchani que compre de don Francisco Arguello de que ten / [5v] go bastantes recaudos y titulos 
Iten otra chacara y tierras de panllebar en el distrito de Zorata y valle de Larecaxas nombrada Corani y Tuni, que fueron antiguamente de mi abuelo don Fernando Guarachi y sobre que tube muy controbertidos pleitos con mis tios que fueron hijos bastardos y se havian apoderado de las dichas haziendas en que gaste mas de quinze mil pesos en el progreso y difinición de los dichos pleitos hasta que tube centencias de vista revista en la Real Audiencia de La Plata en mi fabor como consta del dicho pleito. Y aunque las dichas haziendas heran mias y de mi hermano don Diego Fernandes Guarache que la mitad me pertenecia y la otra mitad al dicho mi hermano nunca me acudio con plata alguna para las costas de dichos pleitos ni para los tantos y testimonios que saque para resguardo y titulo de mi derecho, y despues de la muerte del dicho mi hermano entro en la mitad que le to / [6r] cava por via de herencia legitima a don Pedro Fernandes Guarache mi sobrino a quien he tenido en mi compañía, quien tampoco me a pagado la cantidad que le tocava de los gastos y costas que e tenido y tube sobre las dichas chacaras que hasta oy se me esta deviendo y asi lo declaro para que consta

Iten asimismo una estancia de pastos y tierras de sembrar generos de la puna en los terminos del pueblo de Tiaguanaco llamada Guacullani que compre por vienes de Francisco de Escobar difunto de que tengo bastantes recaudos en mi poder

Iten otra estancia y tierras de sementeras de la puna en terminos del pueblo de Guacui y Jesús de Machaca nombrada Corpa que compre de Hernando de Tapia que tengo escripturas del precio y venta de ellas

Iten declaro por mis vienes otra es / [6v] tancia de pastos en terminos del pueblo de Caquiaviri llamada San Pedro de Pocoraya y Chigcha que la hube y compre por tierras bacas y realengas de Su Magestad por el Juez don Francisco Antonio de la Masueca Alvarado de que tengo titulos confirmados ${ }^{b}$

Iten declaro por mis vienes unas casas de vivienda y morada que tengo en esta Villa en los terminos de la Parrochia de la Consepcion en que oy actualmente estoy viviendo que labre y edifique desde sus simientos con mi hazienda en que tengo hechas bodegas y aposentos quiero y es mi voluntad que todos los dichos mis hijos vivan y posean las dichas casas

Iten declaro por mis vienes unas casas de vivienda y morada con sus bodegas y una tienda de pulperia en la villa de Oruro en el barrio de Conchopata el Chico mando que todos los arrendamientos de la dicha pulperia se apliquen para los redificios que nesesitare y techar / [7r] y reparar las dichas casas y bodegas y que mis hijas asistan y vivan en ellas

Iten declaro por mis vienes un sitio que tengo en la ciudad de La Paz en los altos de San Francisco que tienen empesados a sacar los simientos mando que los dichos mis herederos las prosigan y edifiquen con mi hazienda y todos los dichos mis hijos vivan en ellas

Iten declaro por mis bienes dos mil quinientos y veinte carneros de ganado de la tierra en seis manadas de los cuales han de yr los un mil a sacar vino de los valles de Moquegua con seis mil pesos que tiene para este efecto doña Lucrecia Guarachi mi hija en su poder y los demas restantes sean para sacar las cosechas de las nuebe chacaras que tengo en los dichos valles y se lleven las cargas de mayz y trigo a San Antonio de Esquilache y a otras partes y con lo / [7v] [pro]cedido alquile y mingue albañiles canteros y demas oficiales para el edificio y fabrica del dicho mi pueblo 
Iten declaro por mis vienes mil y setenta cabezas de obejas de la tierra en cinco manadas de cuya cantidad desde luego aplico ciento y cinquenta cabesas de la tierra para las recogidas de el dicho mi pueblo cuyos multiplicos y aumentos han de ser para los gastos nesesarios que hubieren menester y otras setenta se le han de dar a los herederos de Francisco Calli difunto y de no haverlos se los den y entreguen a su ayllo Sulcatiti de donde era su sobrino

Iten declaro que tengo en la chacara y haziendas de Sococoni ochocientas obejas de Castilla las quales se han de quedar en ellas para que de su estiercol se guanen y beneficien las chacaras de mais del dicho valle

Mas declaro por mis bienes dos / [8r] mil obejas de Castilla en tres manadas de las quales las mil se han de partir a quinientas doña Lucrecia y doña Maria Guarachi mis hijas lejitimas y las otras mil para el sustento de las recogidas de el dicho mi pueblo

Iten declaro seiscientos carneros de Castilla mando que se vendan de contado y se tengan por mis vienes

Iten declaro por mis vienes otras setecientas obejas que tengo en mi pueblo las quales doy $\mathrm{y}$ aplico a la cofradia de las benditas animas del Purgatorio para que de sus aumentos y multiplicos se manden decir misas para las dichas animas que aunque eran quatrocientas tan solamente las que estaban aplicadas oy de presente se an multiplicado hasta setecientas y asi quiero y es mi voluntad que sean para el sufragio de las benditas animas del dicho mi pueblo /

[8v] Iten declaro otras mil obejas de Castilla que estan en la estancia de Guacullani mando que de ellas se den quatrocientas obejas para las hijas de Maria Orcoma del pueblo de Curaguara y que no las pueda vender ni enagenar sino antes procurar el aumento de ellas para el sustento y alimento de dichas sus hijas porque asi es mi voluntad

Iten declaro por mis vienes seiscientas y cinquenta vacas de vientre parederas en dos manadas que estan oy en pie para que aya multiplicos de ellas, y aya de donde sacar y hazer yuntas de buyes [sic]

Iten declaro doscientos y quarenta toros de tres quatro años en dos manadas mando que todos se vendan o que se haga matansa de ellos

Iten declaro ciento y setenta novillos que asimesmo mando se vendan cuyo prosedido se tenga por mis vienes /

[9r] Iten declaro que ya tengo pagados y gastados dose mil pesos por mi pueblo comprando las tierra que le competen y le estan adjudicados en las composisiones, pleitos, confirmaciones, titulos y salarios y otros gastos en que los dichos mi alvaseas reconoseran por el ajustamiento liquido la cantidad de los dichos dose mil pesos las quales tierras y estancias las dejo y aplico a la comunidad de los indios del dicho mi pueblo de Jesus de Machaca para que tengan todos en comun sus ganados y siembren y cultiben sus tierras y les pido y encargo con todas veras me encomienden a Dios

Iten declaro que reconociendo la quiebra y disipacion del dicho mi pueblo Jesus de Machaca y la suma probreza en que cada dia / [9v] yba aumentandose procure por buen govierno y consultas de mis principales reparar el daño si posible fuese disponiendo algunos yndios reducidos que sobravan demas de los nesesarios de la mita de Potosi diesen en cada un año ciento y quarenta pesos para ayuda de pagar resagos de la dicha mita de Potosi y suplementos de las tasas y otros servicios pencionales; y que no haviendo 
dichos resagos ni suplementos, esta cantidad de cada un año se fuese poniendo en deposito para comprar haviendo cantidad considerable una chacara y hazienda de importancia en los valles para la comunidad de los dichos indios del pueblo de Jesus de Machaca de cuyos efectos y frutos se fuesen aprovechando en las nesesidades y tributos y tubiesen de donde sustentarse y en particular / [10r] los pobres indios desvalidos lo qual teniendo efecto por tres a quatro años, como paresera de unos libros que para este efecto se formaron desde el año que es principio hasta cuando duró y seso esta combeniencia comun en que esta asentado lo que se cobrava nombrandose cobradores y depositarios los quales teniendo ocacion y usando mal de esta diligencia gastaron y consumieron la dicha plata o la mayor parte de lo que cobraron, sin que yo me aprovechase de cosa alguna porque no entro en mi poder ni un tan solo maravedi, con que por no estar la plata junta ni haver hazienda no se compraron para la dicha comunidad. $Y$ respecto de haver sido yo, el autor con acuerdo y consentimiento del Maestro de Campo don Gar / [10v] cia de Hijar y Mendosa corregidor y justicia mayor que fue en este tiempo de la dicha provincia de Pacajes para descargo de mi consciencia quiero y es mi voluntad que se compren unas haziendas y chacaras que ymporte su valor y justo precio hasta dies o dose mil pesos que son los que pareseran cobrados en los dichos libros cuia cantidad de los dichos dose mil pesos los a de dar y pagar don Pedro Fernandes Guarache quien me los deve por escripturas e instrumentos que mando se cobren y se tengan por mis vienes, y de ellos se compren las dichas chacaras para el comun provecho y utilidad de los dichos yndios; por cuya causa algunos del dicho mi pueblo mal aconsejados y persuadidos de algunas personas que se han querido mostrar enemigos mios sin haverles dado ocacion de queja ni motibo de sentimiento me han puesto pleito y capitulos de demanda / [11r] en el Govierno Superior de estos reinos por exorvitantes cantidades que disen persivi de ellos en la forma y pretexto tan justo que tube para alivio y conserbacion del dicho mi pueblo que todos los dichos capitulos caresen de relacion verdadera y asi lo declaro para el paso en que estoy y la estrecha cuenta que he de dar a Su Divina Magestad que solo hallo en mi conciencia que por aver sido el autor de este buena obra debo satisfacer los dichos diez o dose mil pesos que ymportarian los indios colquehaques que todo constara en los libros a que me remito

Iten declaro por mis vienes mucha cantidad de ropa de bestir de hombre y muger y muchos hovillos y caytos de lana de barios colores y otras menudencias, payzes [sic], retablos, cajas, escriptorios, cuyas, sillas, y bufetes y otros aderentes y trastos /

[11v] Iten dos petacas de plata labrada de torno y de martillo nueba que esta en poder de doña Lucrecia mi hija que resevio en su poder hasta tanto que se de fin y remate a la obra de la iglecia, por si acaso fuere necsesario empeñarla faltando dinero para la satisfaccion y paga de lo que susediere comprarse y despues de ello, si susediere para las obras de recogimiento y hospital

Iten declaro que tengo siete centillos dos de perlas que el uno de ellos costo trescientos y cinquenta pesos por ser las perlas grandes.- $Y$ otro ciento y diez.- Otro de esmeraldas que costo ciento y veinte.- otro de piedras blancas o dobletes que me costo ochenta pesos.otro de rubies que era de Matheo Pablo y lo tengo por cuenta de Pablo Sullcata que baldra hasta cien pesos

Iten mas dos centillos de piedras coloradas que estan en poder de la dicha doña Lucrecia mi hija y un centillo [...] / [13r] [...]sos al dicho maestro de Campo don Antonio de 
Astorga mas no se si se los aya dado y asi de la persona que los hubiere resevido se cobraran

Iten declaro que me deve Sebastian de Mena un mil pesos que le di y preste socorriendole en peligro de su vida porque el corregidor que entonses era le quizo ahorcar porque se los devia y tubo la horca puesta para executar su yntento y yo movido de toda piedad se los pague al dicho corregidor con que se quito la horca y se suspendio la sentencia

Iten el secretario Sebastian Fernandes Sapata Escribano Publico en la ciudad de La Paz me deve cuarenta pesos

Iten el contador don Antonio de Vargas y Villagomez Juez Oficial Real de la ciudad de La Paz me deve trescientos pesos corrientes por una / [13v] cedula que la tiene una india nombrada Ana que esta en los altos de nuestro Padre San Francisco de la ciudad de La Paz Iten declaro que Francisco Miranda que vive y reside en el pueblo de Guarina me deve trescientos pesos y le tengo en prendas unos titulos y escripturas de unas tierras a quien conose y sabe de ello don Pedro Fernandes Guarachi mi sobrino

Iten declaro que Francisco de Morales dueño de Ingenio en Chaque me deve quinientos y ochenta y siete pesos

Iten don Pedro de Yebra Pimentel difunto y sus vienes me deven tres mil y trescientos pesos corrientes de que tengo escriptura que otorgó en mi fabor con hipoteca especial del Ingenio que dejo en esta Villa y sobre los dichos vienes ay pleito pendiente en la Real Audiencia de La Plata / [14r] a que estoy opuesto y pagados letrado y procurador Iten me deve el maestro don Fernando de Castillo y Herrera cura y vicario del pueblo de Caquiaviri doscientos y cinquenta pesos corrientes

Iten el capitan Andres Muños de Zespedes vesino de esta villa me debe noventa y un pesos y medio que con esta plata se a de ayudar a mas cantidad para comprar mulas chucaras

Iten declaro por mis vienes otras cantidades de pesos que me estan deviendo otros españoles de que tengo escripturas y cedulas en mi poder mando que mediante ellas se cobren y se tengan por mis bienes

Iten declaro que los casiques e indios de la provincia de Pacajes me deven muchas cantidades de pesos que les e dado y prestado

Primeramente don Martin Condori casique de Curaguara / [14v] un mil y seiscientos y cinquenta pesos

Iten por una libransa del maestro de Campo don Joseph de Torres y Zuniga un mil doscientos setenta pesos.- mas treinta pesos de unos sestos de coca.- mas ciento y veinte pesos de unas botijas de vino que le di en esta villa que fueron dose a dies pesos cada una que por todo montan tres mil y setenta pesos

Iten don Thomas Canque casique del pueblo de Calacoto me deve mil y seiscientos y mas pesos.- Mas don Diego Menacho casique del pueblo de Caquiaviri me deve un mil y trescientos pesos

Iten don Francisco Cirpa casique del dicho pueblo de Caquiaviri deve un mil cient pesos con mas otros quatrocientos y asimimsmo por una fianza cinquenta pesos 
Iten don Christoval Quispe / [15r] Guanaco casique de San Andres de Machaca me deve en dos partidas que le di la una ves seiscientos pesos y la otra setecientos que juntos hasen un mil trescientos pesos de que tiene otorgada escripturas de estas dos cantidades

Iten don Pedro Gracia casique de el dicho pueblo de San Andres de Machaca y sus hermanos me deven un mil y quatrocientos pesos

Iten Sebastian Copa y su hermano Visente casiques del pueblo de Santiago de Machaca me deven un mil ciento y veinte pesos por el valor de ciento y dose botijas de vino que les di y preste

Iten un asistente de Curaguara llamado fulano Guarache / [15v] con su hermano me deven un mil y cuatrocientos pesos

Iten don Alonso Alvarez casique de Guaqui me deve quinientos pesos

Iten don Phelipe Cortes casique del pueblo de Tiaguanaco me deve siete mil pesos como pareseran por escrpturas de obligación que otorgo en mi fabor y estan en mi poder

Iten Antonio Copacalli natural de Tiaguanaco de la parcialidad de Hurisnaya me deve seiscientos pesos

Iten don Phelipe Lope Zirpa casique del pueblo de Viacha me deve seiscientos y cinquenta pesos que quedo pagarme por Magdalena Choqueta su cuñada de que otorgo escripturas; mas me deve por si otros cien pesos /

[16r] Iten don Diego Ori casique de Callapa me deve un mil pesos

Iten don Diego Zirpa casique de Caquiaviri me deve ciento y veinte pesos

Iten don Diego Canqui difunto y sus vienes me deven por mil y quinientos pesos como consta en escriptura que otorgo en mi fabor

Iten don Juan Arcani principal de Viacha me deve doscientos pesos y de otras cuentas antiguas y rezagadas otros doscientos que hacen quatrocientos pesos

Iten Agustin Mamani de Ananzaya natural del pueblo de Viacha me deve doscientos pesos Iten declaro me deve Christoval Condori cient pesos corrientes de los quales me a dado un macho de carga en veinte pesos como paresera de un resivo con que me resta deviendo / [16v] ochenta pesos

Iten don Esteban Callisaya casique del dicho pueblo de Viacha me esta deviendo tres mil y trescientos pesos que consta por escriptura que tiene otorgada en mi fabor

Iten Sebastian Quillo difunto y sus vienes me deven ciento y cinquenta pesos indio natural del pueblo de Viacha

Iten Juan Fernandes de el ayllo Vipaca deve setenta pesos

Iten Geronimo Calli me deve ochocientos pesos que le preste para enterar la tasa

Iten Pedro Guanca me deve un mil pesos por el precio de el vino que saco de mi casa con mas quinientos pesos que le preste para el entero de las tasas

Don Salvador Chuquiguanca me deve quinientos pesos por cuenta de los indios chacaneado / [17r] res aunque jusgo me a dado cien pesos

Pedro Llancaso del ayllo Paguatata me deve un mil pesos de cantidad de botijas de vino que le preste 
Iten declaro que Pedro Fernandes Guarache mi sobrino me deve dos mil y seiscientos y cinquenta pesos por una libranza y sesion de el maestro de campo don Joseph de Torres y Zuniga

Iten mas me deve el dicho don Pedro Fernandes Guarache un mil y seiscientos y cinquenta pesos de lo prosedido de unas botijas de vino que vendio en esta villa exepto lo que pareciera haverme pagado

Todas las quales deudas que constan por escripturas y cuentas de libro y memorias que parecieren demas de las referidas se an de cobrar y tener por mis vienes /

[17v] Iten declaro que tengo ochenta mulas de cavalleria y de carga y los aparejos sobrecargas y lazos y sogas que parecieren mando que las quarenta de ellas se apliquen para que desde luego se saquen madera, tablas y alfagias para enmaderar la Iglecia, hospital y recogidas de el dicho pueblo de Jesus de Machaca y las restantes se puedan reservar para sacar con ellas vino en odres del valle de Moquegua, reduciendolo todo para los gastos de dicha obra, y para ambos tratos se dara plata de mis vienes

Iten declaro que Benito Añari natural del pueblo de Curaguara de Pacages me deve un mil cient pesos que le di en diferentes ocaciones

Iten me deve Alonso Tarquese / [18r] co que fue capitan chico del pueblo de Caquingora y su compañero Jospeh Quispe ocho mil pesos mando se cobren de ellos o de los indios a quienes señalaran

Iten mando que la Iglecia y templo que se hubiere de edificar y lebantar de nuevo sea en Hayomuto o en Chirxiri o en la parte y lugar que le pareciere mejor y mas combeniente a don Pedro Fernandes Guarache y a las demas personas de mejor eleccion con quien se aconsejase

Iten mando que de mis vienes y haziendas se saquen un mil pesos para pagar los maestros canteros de Verenguela que han de haser quatro arcos de piedras blancas que mi sobrino don Pedro Fernandes Guarache tiene consertados, en ochocientos pesos, cada arco en doscientos mas los otros doscientos restantes al cumplimiento de los un mil pesos se paguen / [18v] por las gradas y solero de el altar mayor porque asi es mi voluntad

Iten mando se pague de mis vienes al capitan Reymundo Martel cinquenta pesos por una fianza que hize en su fabor por Juan de la Banda

Iten mando que si los indios aguatires de mis ganados dixeren con juramento que les devo algo de la guarda de mis dichos ganados o de su trabajo personal, doña Lucrecia Fernandes Guarache les pague y satisfaga en cargas de mayz que ay en mis haziendas y justamente sin quedarles a dever cosa alguna porque asi es mi voluntad

Iten mando que de las cosechas de mays del año pasado de setenta y dos se saquen de las haziendas del valle que oy estan en piura [sic] dos mil cargas de mayz y otras tantas de trigo para que se vendan en horden a que / [19r] su prosedido se de por dote a doña Magdalena Guarache mi hija natural que por ser obra pia y haver elejido el estado de religiosa en un combento de monjas le doy dichos tres mil pesos de lo prosedido de ellas, y en caso que no aya lugar luego incontinenti mando que de las botijas de vino que tengo en las bodegas de presente en esta villa, de la primera plata que se hiziere de ellas se saquen los pesos y la pla[ta] que importaren para que se le compren en el valle de Moquegua quatrocientas y cinquenta botijas cuyo prosedido desde luego aplico para la dicha su dote en el combento de monjas 
Iten declaro que tengo por mis vienes un mulato llamado Bartolome Coyuguanca hijo de una negra mi esclava que ia es difunta nombrada Maria / [19v] Angola la qual durante el tiempo que estubo de mi servicio hubo al dicho Bartolome mulato que sera de edad de mas de veinte años cuyo padrino fue en el pueblo de Jesus de Machaca Bartolome Coyuguanca sachristan de la Iglecia de el dicho pueblo mando que el dicho Bartolome sirva y asista a las obras de la dicha Iglecia que se ha de haser, y al hospital y recogidas y acabadas las obras se tenga por mis vienes a disposision de mis hijas doña Lucrecia y doña Maria Guarache

Iten declaro por mis vienes un negro nombrado Antonio de tierra de Angola que sera de edad de veinte a veinte y un años poco mas o menos lo compre en esta villa cuya escriptura de venta tengo en mi poder mando asimesmo que el di / [20r] cho negro como el mulato no se enagenen ni vendan sino acudan a las dichas obras o que hagan viajes a disposision de las dichas mis hijas

Iten mando que las dichas chacaras nombradas Ocovaya y Copachullpa se den a Bonifacio Guarache y a Juan Guarache mis hijos naturales y la chacara de Quiñaspo y Cachacacha se den y dexo a Ignacio y Francisco Guarache, asimismo mis hijos naturales y a don Diego Guarache dejo la chacara y haziendas de Haza en el valle de Cavari, para que las gosen con la bendición de Dios y la mia con calidad que los dichos mi hijos no las puedan vender ni enagenar y el que tratara de vender la parte de chacara que tuviere conforme ba declarado a de perder y pierda el derecho a ellas y entre y buelba al tronco de los / [20v] demas vienes y herederos porque para en este caso los dejo por modo de vincuyo [sic] y que si acaso faltaren y no tubieren hijos dentren los demas hermanos y herederos legitimos porque asi es mi voluntad; pues el motivo que tengo para dejarles las dichas chacaras a los dichos mis hijos naturales es porque estan sugetos a los enteros de la mita en que no ay duda que padeseran siendo capitanes de la dicha mita y sus suplementos como tambien en los de la tasa, que con esto y trabajando como hombres de bien que asi se lo encargo atendiendo lo primero al servicio de Dios guardando su Santa Ley y siendo muy observantes de sus mandamientos divinos y muy debotos de la Serenisima Reyna de los Angeles Santa Maria Madre de Nuestro Señor Jesuchristo en quien confien tener muy buen acierto en todos los su / [21r] sesos y casos que tubieren y les sobrevinieren; como en la lealtad y puntualidad de acudir como buenos basallos al Rey Nuestro Señor tendran muy felizes aumentos en sus haziendas

Y para cumplir y pagar este testamento las mandas disposisiones en el contenidas dejo y nombro por mis albaceas y tenedores de vienes a la dicha doña Lucrecia Guarache y don Diego Guarache mis hijos a ambos a dos juntos y a cada uno de por si ynsolidum y les doy poder y facultad para que entren en los dichos mis vienes y los cobren y recojan vendan y rematen en almoneda publica o fuera de ella y de su prosedido cumplan y paguen este testamento y las mandas de el que para ello les doy el poder y facultad necesaria [con] ${ }^{\mathrm{d}}$ libre y general administracion y quiero les dure este albaseasgo aunque sea pa / [21v] sado el año que el derecho dispone que para ello les prorrogo el demas tiempo que fuere necesario

Y cumplido y pagado este testamento y lo en el contenido y haviendose cumplido y executado las disposisiones que contiene y obras de la Iglecia, hospital y casa de recogidas en el remaniente que de mis vienes quedare deudas derechos y acciones que en qualquier manera me pertenescan dejo instituio y nombro por mis universales herederas a las dichas doña Lucrecia y doña Maria Guarache mis hija legitimas y a los dichos mis hijos 
naturales en la forma que contiene la cláusula que en esta rason tengo dispuesta y a todos para que lo haian y hereden con la vendicion de Dios y la mia atento a que no tengo otros herederos forsosos asendientes ni desendientes que me puedan heredar y ser asi mi voluntad /

[22r] Con lo qual reboco y anulo y doy por ningunos y por de ningun valor ni efecto otros qualesquier testamentos mandas cobdicilos poder y para testar y otras ultimas disposisiones que antes de este testamento aya fecho y otorgado por escripto o de palabra para que no valgan ni hagan fe en jucio ni fuera de el salvo este que agora otorgo que quiero balga por tal y por mi ultima voluntad en cuio testimonio lo otorgue en la villa de Potosi en diez de marzo de mil seiscientos y setenta y tres años y el otorgante a quien yo el escribano doy fe que conos [sic] y que a lo que parese esta en su entero jucio memoria y natural entendimiento asi lo otorgo y firmo de su nombre en presencia de su protector siendo testigos llamados y rogados Andres Muños / [22v] de Zespedes, Antonio de Figueroa, Juan Baleriano, Julian de Miranda y Pedro de Herrera presentes

Iten declaro asimesmo por mis vienes dos chacaras de pan llevar nombradas Acaluco y Timusi de que tengo titulos y recaudos bastantes y es mi voluntad que los frutos de ellas desde luego se den y apliquen para las obras de la dicha Iglecia, hospital y recogidas y acavadas han de bolver al tronco de mis vienes para que mis hijas las hereden con la bendicion de Dios [y la mia] y les pido que respecto de encaminarse al servicio de Dios Nuestro Señor y culto de su Iglecia tengan a bien lo contenido en estas cláusulas y concientan en ellas fecho ut supra testigos los dichos.- $[D o n]^{\mathrm{f}}$ Bernardo de Naguzia.- Don Gabriel Fernandes Guarache.- Ante mi / [23r] Francisco Ximenes escribano publico.

Documento 2. Codicilo de don Gabriel Fernández Guarachi. Jesús de Machaca, 13 de junio de 1673. Archivo de La Paz, Juzgado de Pacajes, Caja 11 (1730-1749): “Espediente seguido sobre las tierras de la pirca de Chicchas canton Jesus de Machaca", folios 20r-22r.

[20r] (...) Cobdicilio. En el nombre de Dios Todo Poderoso con cuia Gracia todas las cosas tienen buen principio, loable medio y dichoso fin, sea notorio a los que esta carta y escriptura de testamento vieren como yo don Gabriel Fernandes Guarache natural y cacique principal y governador de el pueblo de Jesus de Machaca provincia de Pacaxes hijo lexitimo de don Pedro Guarache cacique principal y governador que asimesmo fue del dicho pueblo y de doña Maria Casi su lexitima muger ambos difuntos estando emfermo de la emfermedad que Dios a sido servido de darme y en mi entero juisio y entendimiento tal qual Dios fue servido de darme y por ser cosa natural la muerte y no saver el dia y la ora de ella / [20v] y que no me coxa del todo desdichado es mi voluntad haser y ordenar las cosas que ymportan a mi alma y poniendolas en efecto y creiendo como firmemente creo y comfieso en el misterio de la Santisima Trinidad Padre Hijo y Espiritu Santo tres personas distintas y un solo Dios verdadero en unica esencia y en todo aquello que cree y comfiesa nuestra Santa Madre Yglesia Catholica Romana, devajo de cuia fe y creencia he vivdo hasta oy y protesto vivir en lo restante de mi vida hasta mi fallecimiento con protestacion que buelvo a haser que si por la gravedad de la emfermedad que adolesco a ylucion del Demonio nuestro capital enemigo o por otra cualquiera causa o accidente o otra cosa dijere o diere a entender al contrario no sea en ci ninguna ni de ningun valor ni efecto y para todo ymboco con todo afecto y reverencia por 
mi abogada e yntersesora a la Purisima Virgen Santa Maria madre del Vervo Eterno y a los gloriosos apostoles San Pedro y San Pablo y al arcangel San Gabriel y a todos los demas santos de la corte del cielo para que sean medianeros con Su Divina Magestad que perdone mis culpaz y pecados y deseando como deseo poner mi alma en carrera de salvacion y devajo de la creencia referida y de todo aquello que deve creer y comfesar por donde nuestra Santa Madre Yglecia / [21r] Romana hago y hordeno mi testamento ultima y postrimera voluntad en la forma y manera siguientes $=$

Primeramente encomiendo mi alma a Dios Nuestro Señor que se crio y redimio con su presiosa sangre pacion y muerte y el cuerpo a la tierra de que fue formado =

Yten mando que quando Dios fuere servido de llevarme de esta presente vida sea mi cuerpo enterrado en este pueblo en la capilla maior abaxo de las gradas del altar maior y mi cuerpo sea revestido con el avito del Señor San Francisco y se pague por el la limosna acostumbrada como esta puesto en el aransel con los cargos que tiene y es mi voluntad =

$\mathrm{Y}$ asimesmo les dexo a los dichos yndios del comun el citio y parexe que llaman Chixcha y Pocoraya y sus linderos que estan en los terminos del pueblo de Caquiavire para que en este paraxe puedan pastear sus ganados como sembrar las legumbres que les pareciere cuios titulos se los entrgue por mis alvaseas a los dichos yndios esta manda honerosa les hago a los dichos yndios por el amor que les tengo =0jo

Pie. Con lo qual se acavo este cobdicilio revocando las clausulas que por este se cita dejando en su fuersa y vigor el dicho testamento en quanto a las clausulas que no se hase mencion y para / [21v] cumplir con lo contenido de este cobdicilio mandas y demas disposisiones dexo y nombro por mis alvaseas y herederos de vienes a doña Lucrecia Fernandez Guarachi don Diego Guarache don Bonifacio y Ygnacio Fernandez Guarachi mis hijos a todos juntos y a cada uno de por ci ynsolidum y les doi poder y facultad para que entren en los dichos mis vienes y los cobren y recojan vendan y rematen en almoneda publica o fuera de ella y de su prosedido cumplan y paguen este cobdicilio y las mandas de el que para ello les doi el poder y facultad necesaria con libre y general administracion y quiero les dure este alvaseasgo aunque sea pasado el año que el derecho dispone que para ello les prorrogo el demas tiempor que fuere nesesario =

Cumplido y pagado este cobdicilio y lo en el contenido y haviendose cumplido y executado las disposisiones que contiene y obras de la yglecia hospital y casa de recojidas en el remaniente que de mis vienes quedare deudas derechos y acciones que en qualquier manera me prestenescan dexo e ynstituio y nombro por mis universales herederas a las dichas doña Lucrecia y doña Maria Fernandes Guarachi mis hijas lexitimas y a los dichos mis hijos naturales en la forma que con / [22r] tiene la clausula que en esta rason tengo dispuesta y a todos para que lo ayan y ereden con la vendicion de Dios y la mia atento a que no tengo otros herederos forsosos asendientes ni desendientes que me puedan heredar y ser asi mi voluntad. Testigos el Lizenciado Alonso de Uribe Basurto cura y vicario en inter en este dicho pueblo el Lizenciado don Pedro Flores clerigo presvitero el Bachiller Fernando de Vargas Machuca clerigo presvitero el capitan Juan Garcia Trexo Paniagua el alfereres Diego de Vargas Machuca y don Lorenso Carlos Ynga presentes que fueron por mi llamados y rogados. Y lo firmaron los dichos testigos. Fecho en este pueblo de Jesus de Machaca provincia de Pacaxes en trece de junio de mil y seiscientos y setenta $\mathrm{y}$ tres años $=$ Entre renglones $=\mathrm{s}=$ un mil pesos $=$ Valga $=$ Don Gabriel Fernandes Guarachi = Alonzo de Uribe Basunto don Pedro Jacinto Flores de Abalos Joseph de Contreras 
Fernando de Vargas Machuca Diego de Vargas Machuca Juan Garcia Trejo Paniagua don Lorenzo Carlos Ynga

Documento 3. Testamento de Doña Lucrecia Fernández Guarachi. Asiento de minas de San Juan Berenguela, $1^{\circ}$ de junio de 1694 . Incluye poder para testar otorgado a su hermano, don Bonifacio Fernández Guarachi, y al Bachiller Miguel de Larrea y Mudarra, cura de Cepita. Jesús de Machaca, 4 de febrero de 1694. Archivo de La Paz, Juzgado de Pacajes, Caja 11 (1730-1749): "Espediente seguido sobre las tierras de la pirca de Chicchas canton Jesus de Machaca", folios 29r-39r.

[29r] (...) Testamento. En nombre de Dios Todo Poderoso Amen con cuio principio se tiene buen medio y dichoso fin, sea notorio a todos los que la presente escritura y ultima voluntad vieren como nos el Bachiller Miguel de Larrea y Mudarra cura ynter del beneficio de Santa Cruz y San Sevastian del pueblo de Sepita de la provincia de Chucuito y don Bonifacio Fernandes Guarachi principal del pueblo de Jesus de Machaca de esta provincia decimos que por quanto doña Ana Lucrecia Fernandez Guarachi ya difunta hija lexitima y coeredera de don Gabriel Fernandez Guarachi su padre cacique / [29v] y governador que fue del dicho pueblo de Jesus de Machaca, otorgo segun parese su testamento y ultima voluntad en diez y siete de septiembre del año pasado de mil seiscientos ochenta y quatro ante testigos a falta de escrivano o jues y paerser que haviendo Dios Nuestro Señor dadole salud corrio el dicho testamento hasta 4 dias del mes de febrero de este presente año 1694 que hallandome la susodicha molestada de grave emfermedad y por no poder haser nuevo testamento otorgo poder a nuestro favor como albaseas y uno de los herederos para que en su nombre y representando su mesma persona, corrigiesemos algunas clausulas del dicho testamento citado y añadiesemos las que en su lugar nos comunico cuio poder que parese esta comprovado ante el capitan Diego Pacheco de Chaves theniente general de esta provincia por Su Magestad cuio tenor a la letra que uno y otro es como se sigue =

Poder. En el pueblo de Jesus de Machaca en quatro dias del mes de febrero de mil seisicentos nobenta y quatro años ante mi don Pedro Condori alcalde hordi / [30r] nario de este dicho pueblo y el escribano de cavildo Salvador Guarachi y testigos de yuso que al fin iran mencionados parecio doña Ana Lucrecia Fernandez Guarachi a quien sertifico que conosco natural de este pueblo hija lexitima de don Gabriel Fernandes Guarachi y de doña Maria Hachama, y estando enferma, del cuerpo y sana de la voluntad y entendimiento dijo que creya en todo aquello que debe creer como berdadera christiana y todo aquello que enseña y manda la Santa Madre Yglecia dixo que manda y es su voluntad se guarde y cumpla el testamento ultimo que en este dicho pueblo otorgo ante el alcalde hordinario y testigos y porque algunas clausulas de dicho testamento es menester quitar y añadir otras, y porque el mal que padese va agravando y estas a dias las tiene comunicadas al Lizenciado Miguel de Larrea y Mudarra, y a don Bonifacio Fernandes Guarachi su hermano para que en la forma que les tiene comunicado sin quitar ni añadir les dava y dio su poder cumplido bastante qual de derecho se requiere y es necesario para que en su nombre otorguen cobdicilio y representando su propria persona como si presente estubiera los dichos / [30v] puedan haser y ordenar dicho cobdicilio en presencia de mi sobrino don Joseph Fernandes Guarachi a quien de la mesma suerte le tengo comunicado y pido asista al dicho otorgamiento y a mis podatarios pido y ruego y suplico acudan con la legalidad que se requiere a descargo de mi conciencia y todo lo qual fuere fecho y otorgado por los dichos Miguel de Larrea y Mudarra y don Bonifacio Fernandes Guarachi mi hermano en rason de lo que tengo mencionado por birtud de este poder, la otorgante dixo que para ahora y en todo tiempo lo aprovava, y ratificava como si fuera fecho por la 
otorgante y pida y suplique a las justicias y jueses de Su Magestad den por valido sierto y verdadero lo que los dichos otorgaron para cuia firmesa y cumplimiento obligo sus bienes avidos y por aver. Y dio poder a todas las justicias y jueses de Su Magestad a cuio fuero se sometio y renuncio el suio proprio y la ley que dise que el autor debe seguir el fuero del reo para que a su cumplimiento le compelan sus vienes como por sentencia pasada por jues competente en cosa jusgada y renuncio todas las leyes / [31r] y derechos de su favor y la general que lo prohive para cuio cumplimiento y firmesa nombro por sus herederos unibersales a don Bonifacio Fernandes Guarachi y a don Juan Fernandes Guarachi sus hermanos para que con la bendicion de Dios y la suia gosen y posean los bienes que parecieren y pertenesieren a la otorgante pagado funeral mandas pias y forsosas y nombro por sus albaseas a dicho Lizenciado Miguel de Larrea Mudarra y a don Bonifacio Guarachi. E yo dicho alcalde hordinario y escribano de cavildo en lo que a lugar sertifico y doi testimonio verdadero de que aci lo otorgo siendo testigos rogados y llamados el maestro Pedro Muños del Castillo, cura cuadjutor de este dicho pueblo, Miguel ortis de Sensano don Joseph de Uscamaita don Miguel Fernandes Guarachi que lo firmaron conmigo y a ruego de la otorgante que no firmo por no saber rogo a un testigo a firmar por ella $=\mathrm{Y}$ todo paso con asistencia de mi governador, a ruego de la otorgante y por testigo Pedro Muños del Castillo = Don $/$ [31v] Pedro Condori $=$ Joseph Real de Sespedes = Miguel de Machicao $=$ Don Joseph Uscamaita $=$ Juan Ortis de Sensano $=$ Don Miguel Fernandes Guarachi. Ante mi Salvador Guarachi escribano de cavildo =

Petision. Don Bonifacio Fernandes Guarachi y don Juan Fernandes Guarachi herederos y alvaseas de doña Lucrecia Fernandes Guarachi paresemos ante Vuesa Merced como mas aya lugar en derecho y decimos que la dicha doña Lucrecia mi hermana otorgo poder en bastante forma, so cuya disposision fallecio y el dicho poder otorgo ante un alcalde y escrivano de cavildo de este pueblo y testigos que se hallaron presentes y para que usemos del derecho que nos compite tenemos nesesidad de que se compruebe atento a lo que $=\mathrm{A}$ Vuesa Merced pedimos y suplicamos aia por pesentado el dicho poder, $\mathrm{y}$ en su comformidad mande se compruebe judicialmente y fecho se nos buelva originalmente consediendonos el derecho que nos compete en los casos nesesarios que en mandarlo asi Vuesa Merced nos hara justicia con merced que esperamos de la piedad de Vuesa Merced y juramos a Dios y a la Cruz en lo necesario etcetera $=$ Don Bonifa $/$ [32r] cio Fernandes Guarachi $=$ Don Juan Fernandes Guarachi $=$

Decreto. Por presentado el poder y en su comformidad y atento a lo que piden y aver algunos naturales en el dicho poder mando sean llamados los contenidos en el dicho poder ante quien otorgo la dicha doña Lucrecia Fernandes Guarachi y se compruebe en la forma hordinaria nombrando ante todas cosas ynterpretes y fecho se traigan los autos para probeer lo que combenga. El capitan Diego Pacheco de Chaves theniente general de esta provincia de Pacaxes por Su Magestad probeyo el decreto de suso y mande autuando ante mi judicialmente a falta de escrivano publico ni real siendo testigos Diego Delgado de Figueroa y don Joseph Pacheco de Chaves quienes firmaron conmigo en el pueblo de Jesus de Machaca en ocho dias del mes de febrero de mil seiscientos nobenta y quatro años = Diego Pacheco de Chaves, Diego Delgado de Figueroa Joseph Pacheco de Chaves =

Nombramiento de interprete. En el pueblo de Jesus de Machaca provincia de Pacaxes en ocho dias del mes de febrero de mil y seiscientos nobenta y qua / [32v] tro años el capitan Diego Pacheco de Chaves theniente general de esta provincia de Pacaxes por Su Magestad en comformidad del decreto antesedente para la comprovacion que piden don Bonifacio Fernandes Guarachi y don Juan Fernandes Guarachi alvaseas y herederos de doña 
Lucrecia Fernandes Guarachi y se le manda dar, nombro por ynterpretes a don Sevastian Fernandes Guarachi y a Pedro Lopes Hilatico personas ynteligentes en ambas lenguas de los quales siendo presentes resevi juramento por Dios Nuestro Señor y una señal de Cruz so cuio cargo prometieron haser bien y fielmente la interpretacion a su leal saber y entender si asi lo hisieren Dios Nuestro Señor les aiude y al continuo les demande a cuia conclusion dijeron si juramos y amen, y lo firmaron ante mi a falta de escribano publico ni real siendo testigos Diego Delgado de Figueroa y Joseph Pacheco de Chaves quienes firmaron conmigo $=$ Diego Pacheco de Chaves Pedro Lopes Hilatico $=$ Don Sevastian Fernandes Guarachi Diego Delgado de Figueroa, Joseph de Pacheco y Chaves $=$

Declarazion. En dicho dia mes y año dichos yo el theniente / [33r] general hize compareser ante mi a don Pedro Condori alcalde hordinario de este dicho pueblo y por ynterpretasion de los ynterpretes demas de ser bersado en el ydioma castellano ante quien se otorgo dicho poder de quien resevi juramento por Dios Nuestro Señor y una señal de Cruz en la forma hordnaria y siendole mostrado el poder y que reconosiere su firma, la reconosio una firma que dise don Pedro Condori y dijo ser cierto que paso ante el el qual se leyo en su presencia y de los demas testigos y que firmo un testigo por la dicha otorgante porque no savia firmar y esta es la verdad so cargo del juramento que fecho tiene y lo firmo conmigo autuando ante mi a falta de escribano publico ni real siendo testigos Joseph Pacheco de Chaves y Diego Delgado de Figueroa quienes firmaron conmigo. Diego Pacheco de Chaves $=$ Don Pedro Condori $=$ Pedro Lopes Hilatico $=$ Don Sevastian Fernandes Guarachi Joseph Pacheco de Chaves $=$ Diego Delgado de Figueroa $=$

Declarazion. En dicho dia mes y año dichos yo / [33v] el dicho theniente general hize compareser ante mi al maestro Pedro Muños del Castillo cura cuadjutor de este dicho pueblo y vicario de el de quien resevi juramento por Dios Nuestro Señor y una señal de Cruz en bervo saserdotis puesta la mano en el pecho en forma de derecho so cargo de el prometio decir verdad. Y siendole mostrado una firma que dise a ruego del otorgante y por testigo Pedro Muños del Castillo que esta en el dicho poder dixo ser suia y averse hallado persente al tiempo que la dicha doña Lucrecia Fernandes Guarachi otorgo el dicho poder y que firmo por la dicha otorgante a ruego por no saber firmar y esta es la verdad de lo que paso. Y que estava la dicha doña Lucrecia en su entero jucio porque preguntava y respondia con entero conosimiento y asi lo declaro so cargo del juramento que fecho tiene y lo firmo conmigo ante mi actuando judicialmente a falta de escribano publico ni real siendo testigos Joseph Pacheco de Chaves y Diego Delgado $=$ Diego Pacheco de Chaves $=$ Pedro Muños del Castillo, Diego $/[\mathbf{3 4 r}]$ Delgado de Figueroa $=$ Joseph Pacheco $=$

Declarazion. En dicho dia mes y año para la dicha comprobacion hise pareser ante mi Miguel de Machicado de quien resevi juramento por Dios Nuestro Señor y una señal de Cruz en forma de derecho so cargo del prometio decir verdad. Y siendole mostrado una firma que esta en el dicho poder que dise Miguel de Machicado dixo ser suia y que se hallo persente al otorgamiento del dicho poder que otorgo la dicha doña Lucrecia y se leyo en su presencia y que firmo el maestro Pedro Muños del Castillo a ruego de la otorgante por no saber firmar y que esta es la verdad so cargo del juramento que fecho tiene y lo firmo conmigo ante mi a falta de escribano publico ni real siendo testigos Joseph Pacheco de Chaves y Diego Delgado que lo firmaron conmigo. Diego Pacheco de Chaves = Miguel de Machicado Diego Delgado de Figueroa $=$ Joseph Pacheco de Chaves $=$

Declarazion. En dicho dia mes y año para la dicha comprobacion hise compareser ante mi a Joseph Real de Sespedes de quien resevi juramento por Dios Nuestro Señor y una 
señal de Cruz en forma de / [34v] derecho. Y siendole mostrado una firma que dise Joseph Real de Sespedes en el dicho poder que otorgo doña Lucrecia Fernandes Guarache y dijo ser suia y que se hallo al otorgamiento del poder el qual se leyo en su presencia y de los demas testigos y que firmo un testigo por la otorgante por no saber firmar y esta es la verdad so cargo del juramento que fecho tiene y lo firmo conmigo y ante mi a falta de escribano publico ni real siendo testigos Diego Delgado de Figueroa y Joseph Pacheco de Chaves. Diego Pacheco de Chaves, Joseph Real de Sespedes. Diego Delgado de Figueroa = Joseph Pacheco de Chaves $=$

Declarazion. En dicho dia mes y año para la dicha comprobacion yo el dicho theniente general hize pareser ante mi a Juan Ortis de Sensano de quien resevi juramento por Dios Nuestro Señor y una señal de Cruz en forma de derecho. Y siendole mostrado una firma que esta en el dicho poder que otorgo la dicha doña Lucrecia Fernandes Guarache que dise Juan Ortis de Sensano y dijo ser suia y que se hallo al otorgamiento del dicho poder y que la otorgante estando en su entero juicio lo hiso y se le leyo el dicho / [35r] poder y esta es la verdad so cargo del juramento que fecho tiene y lo firmo conmigo y ante mi a falta de escribano publico ni real siendo testigos Diego Delgado de Figueroa Joseph Pacheco de Chaves que firmaron conmigo $=$ Diego Pacheco de Chaves $=$ Juan Ortiz de Sensano Diego Delgado de Figueroa $=$ Joseph Pacheco de Chaves $=$

Declarazion. En el dicho dia mes y año dichos yo el dicho theniente general hise pareser a don Miguel Fernandes Guarachi de quien resevi juramento por Dios Nuestro Señor y una señal de Cruz en forma de derecho. Y mostradole una firma que dise don Miguel Fernandes Guarachi que esta en el dicho poder, dixo ser suia y que se hallo presente al otorgar y que estando en su entero juicio se leio el dicho poder y se le dio a entender y bino en el la dicha doña Lucrecia y que esta es la verdad so cargo del juramento que fecho tiene y lo firmo conmigo autuando ante mi jusicialmente a falta de escribano publico ni real siendo testigos Diego Delgado de Figueroa y Joseph Pacheco de Chaves = quienes firmaron conmigo y por interpretasion de los dichos ynterpertes demas de ser ladino en la lengua castellana, quienes lo firmaron $=$ Diego Pa $/[35 \mathrm{v}]$ checo de Chaves $=$ Don Miguel Fernandes Guarachi Pedro Lopes Hilatico $=$ Don Sevastian Fernandes Guarache $=$ Joseph Pacheco de Chaves $=$ Diego Delgado de Figueroa $=$

Declarazion. En dicho dia mes y año yo el dicho theniente general hise pareser a don Joseph Usacamaita de quien resevi juramento por Dios Nuestro Señor y una señal de Cruz y so cargo de el prometio decir verdad por ynterpretacion de los dichos ynterpretes. $Y$ siendole mostrado una firma que dise don Joseph Uscamaita en el dicho poder que otorgo la dicha doña Lucrecia dixo ser suia y que se hallo presente al otorgamiento estando en su entero juicio otorgo la dicha Lucrecia a quien se lo hiso entender de verbo adbervu y bino en el y que esta es la verdad so cargo del juramento que fecho tiene y lo firmo conmigo y dichos ynterpretes y autuando ante mi judicialmente a falta de escribano publico ni real siendo testigos Diego Delgado de Figueroa y Joseph Pacheco de Chaves, quienes lo firmaron conmigo $=$ Diego Pacheco de Chaves $=$ Don Joseph Uscamaita $=$ Pedro Lopes Hilatico $=$ Don Sevastian Fernandes Guarachi $=$ Joseph Pacheco de Chaves $=$ Diego Delgado de Figueroa $=/$

[36r] Declarazion. En dicho dia mes y año yo el dicho theniente general hise pareser ante mi a Salvador Guarachi escrivano de cavildo de este pueblo a quien resevi juramento por Dios Nuestro Señor y una señal de Cruz en forma de derecho y por ynterpretasion de los ynterpretes demas de ser versado en la ydioma castallana. $\mathrm{Y}$ aviendole mostrado una 
firma que dise ante mi Salvador Guarachi escrivano de cavildo que esta en el dicho poder que otorgo la dicha doña Lucrecia Fernandes Guarachi dijo ser suia como tal escrivano de cavildo por ser causa de naturales, ynterpuso su autoirdad y que paso todo lo otorgado ante el y siendole leydo el dicho poder a la dicha doña Lucrecia haviendole dado a entender dijo que asi lo otorgava, y que era su voluntad postrimera y que esta es la verdad so cargo del juramento fecho y lo firmo conmigo y ante mi a falta de escribano publico ni real siendo testigos Diego Delgado de Figueroa y Joseph Pacheco de Chaves, quienes firmaron conmigo y los ynterpretes $=$ Diego Pacheco de Chaves $=$ Salvador Guarache $=$ Pedro Lopes Hilatico $=$ Don Sevastian Fernandes Guarachi Joseph Pacheco de Chaves $=$ Diego Delgado / [36v] de Figueroa =

Auto. En el pueblo de Jesus de Machaca, a nuebe dias del mes de febrero de mil seiscientos nobenta y quatro años el capitan Diego Pacheco de Chaves; theniente general de esta provincia de Pacaxes por Su Magestad. Abiendo bisto el poder que otorgo doña Lucrecia Fernandes Guarache en este pueblo en quatro dias del mes de febrero ante don Pedro Condori alcalde hordinario de este dicho pueblo y Salvador Guarachi escrivano de cavildo de el y testigos y las declaraciones fechas por los dichos alcalde y escrivano y testigos que se hallaron presentes al tiempo del otorgamiento. Digo que apruebo y retifico en bastante forma el dicho poder y demas ynstrumentos suso mencionados para que usen de ellos los dichos alvaseas y erederos en lo que les favoreciere el derecho y en inter ynterpuso su autoridad y jurisdiccion y asi lo probei mande y firme actuando ante mi judicialmente a falta de escrivano publico ni real siendo testigos Diego Delgado de Figueroa y Joseph Pacheco de Chaves que lo firmaron conmigo y mando se le buelba originalmente el poder y la comprovacion = Diego Pacheco de Chaves $=$ Diego Del $/$ [37r] gado de Figueroa $=$ Joseph Pacheco de Chaves

Prosigue. Y usando del dicho poder con acistencia de don Joseph Fernandes Guarachi cacique principal y governador del dicho pueblo de Jesus de Machaca por disposicion de la difunta en que aci asistiese en comformidad de lo que se nos fue comunicado disponemos las clausulas siguientes $=$

Primeramente en las clausulas de nombrar sepoltura erederos y alvaseas declaramos que se cumplio la voluntad de la testadora y por averse aci executado =

Asimesmo nos comunico que ci el comun del pueblo de Jesus de Machaca yntentare algun pleito con sus herederos en tal caso se les quitase la hacienda de Acalloco y la estancia nombrada San Pedro de Coporaya y por otro nombre = Chixcha y tan solamente se les dejase la hacienda nombrada Timusi que esta en la jurisdiccion de Ambana en la provincia de Laricaxa ynmediata a la de Hachalloco que con ella se le satisface a la restitusion que hiso el dicho su padre y deja por heredero de ellas a don Joseph Fernandes Guarachi su sobrino con mas la hacienda / [37v] nombrada Guarata para que lo gose con la vendicion de Dios y la suia que le ruega y encarga ampara a los alvaseas y erederos =

Pie. Con lo qual dejando como desde luego dejamos en su fuerza y vigor las clausulas del testamento citado que otorgo la dicha doña Lucrecia Fernandes Guarache el año de ochenta y quatro. $Y$ en virtud del poder que ba inserto por este cobdicilio que al presente otorgamos en comformidad de lo que se nos comunico por la dicha doña Lucrecia Fernandes Guarache y asi lo juramos comforme a derecho, por el presente anulamos y revocamos otros qualesquier testamento o cobdicilio que fuera del citado hubiere otorgado anci por escrito o de palabra, para que no hagan fe en juicio ni fuera de el y que se este al testamento sitado y a este por su ultima y postrimera voluntad. Y cumplido y 
pagado el testamento y este cobdicilio en el remaniente de todos los vienes de la dicha difunta en comformidad de dicho poder, ele / [38r] gimos y nombramos por sus unibersales erederos a mi el dicho don Bonifacio Fernandes Guarachi mi hermano y a don Juan Fernandes Guarachi mi hermano para que lo gosemos con la vendicion y la de la dicha doña Lucrecia Fernandes Guarache nuestra hermana, y en todos los demas derechos reales y personales que por qualquier bia y manera y derecho le puedan pertenser, y aunque sea pasado el año del alvaseasgo nos prorrogamos al tiempo necesario hasta que se de fin a la ultima voluntad. Y consedemos que de este ynstrumento se den los testimonios que pidieren como sea a partes ynteresadas en cuio testimonio ansi lo otorgamos. E yo el escrivano doy fe conosco a los otorgantes y que a la disposision de este cobdicilio estan buenos al pareser de los cuerpos y en sus enteros jucios que lo otorgaron en saludo y en pie quienes lo firmaron con el dicho don Joseph Fernandes Guarachi y fueron testigos llamados y rogados el Licenciado Christoval Rodrigues de Escovar cura propio de el / [38v] veneficio de Santiago y este aciento de Verenguela, Pedro de Uriarte y Juan de Valente, que es fecho en el aciento de Verenguela de esta provincia de Pacaxes a primero de junio de mil seiscientos nobenta y quatro años =

Y se pone por adbertencia para que despues no aia reparo que todas las enmendatas [?] que disen fabricar aunque estan salvadas ya declaramos que es asi que dise y quiere decir para fabricar la yglecia y no es otro el intento =

Y acimesmo declaramos que la clausula que habla con don Diego Guarache difunto de que le toca a sus hijos la hacienda de Hassa, declaramos que ademas de sus hijos naturales tiene parte doña Bartolina Guarachi muger de don Sevastian Guarache. Asimesmo declaramos que en la clausula que dejo para mi el Bachiller Miguel de Larrea y Mudarra, tocante al pedazo de tierras que menciona la clausula sitada me lo declaro como a su padre espiritual y se lo dijo por estas palabras a mi don Bonifacio Fernandes Guarache a quien nos encargo que nosotros los herederos hiciesen bien por su alma como lo pondremos en execucion; Haviendose escrito a Pedro y Juan de Uriarte no parecieron / [39r] al tiempo del otorgamiento por testigos y asi lo fueron y llamaron al Bachiller Christoval Rodrigues de Escovar dicho cura de este aciento y Juan Velasques y Bernardo de Villagran = Miguel de Larrea Mudarra don Bonifacio Fernandes Guarache don Joseph Fernandes Guarache $=$ Ante mi Ygnacio de Herrera Zevallos escribano publico $=$

\section{NOTAS}

1. El documento forma parte de la Colección "José Rosendo Gutiérrez", obrante en la Biblioteca Central de la Universidad Mayor de San Andres, La Paz (legajo BCUMSA 2216). Según la autora, se trata de un traslado realizado, probablemente, a mediados del siglo XVIII.

2. Archivo de La Paz (ALP), Juzgado de Pacajes (PJJ), Caja 11 (1730-1749). "Espediente seguido sobre las tierras de la pirca de Chicchas canton Jesus de Machaca". El expediente consta de 42 folios, aunque faltan los primeros seis. 


\section{NOTAS FINALES}

a. A partir de aquí, continuamos con la transcripción de Silvia Rivera Cusicanqui, respetando la foliación original.

b. Esta cláusula también aparece transcripta en el documento de 1745. ALP-PJJ Caja 11, "Espediente seguido", ff. 18v-19r.

c. Texto faltante, tal vez debido a roturas o manchas en el documento. De hecho, falta el folio 12 del documento original.

d. Reemplazado: "en".

e. ALP-PJJ Caja 11, "Espediente seguido", f. 20r.

f. ALP-PJJ Caja 11, "Espediente seguido", f. 20r.

\section{RESÚMENES}

La adopción del método escriturario se convirtió en una herramienta clave en el establecimiento de nuevos criterios de legitimidad de los caciques andinos coloniales. La sistematización del dominio colonial también implicó la puesta en juego de los criterios de legitimidad de las autoridades étnicas, quienes debieron redefinir alianzas para reposicionarse en el nuevo escenario político. En este contexto los testamentos de las elites nativas coloniales adquieren gran relevancia como género documental. Durante una estancia de relevamiento en el Archivo de La Paz en junio de 2009, dimos con un expediente de 1745 en el que don Sebastián Cosme, principal y segunda persona de Jesús de Machaca, acompañado por otros principales del pueblo, denunciaba ante el maestre de campo don Juan Antonio de Obaya, juez comisionado por la Audiencia de Charcas, a don Tomás Fernández Guarachi, miembro de la familia cacical, por haberse apropiado ilegítimamente de la estancia de San Pedro de Pocoraya y Chixcha. Aquí presentamos tres documentos contenidos en ese expediente que complementan publicaciones anteriores, y proponemos líneas de reflexión general en el marco de la producción reciente sobre el espacio andino.

The adoption of the writing method became a key tool in establishing new criteria of legitimacy of the colonial Andean Indian chiefs. The systematization of the colonial domain also implied the appearance of the legitimacy criteria of Indian authorities, who ought to redefine alliances to reposition themselves in the new political scenario. In this context, testaments of colonial native elites acquired great documental relevance. During a visit to the Archive of La Paz in June 2009, we found an expedient of 1745 in which don Sebastián Cosme, principal and second in command next to Jesús de Machaca, accompanied by other principals of the village, pressed charges against don Tomás Fernández Guarachi, member of the Indian chief family, before the "maestre de campo" don Juan Antonio de Obaya, appointed judge of the Charcas Audience, for having illegitimately appropriated the estancia of San Pedro de Pocoraya and Chixcha. Here we present three documents contained in this expedient that complement previous publications, and we propose general lines of reflection in the framework of the recent literature on the Andean space. 
ÍNDICE

Keywords: Testaments, Leadership, Indigenous writing, Native elites, Ayllu

Palabras claves: Testamentos, Liderazgo, Escritura indígena, Elites nativas, Ayllu

\section{AUTOR}

\section{ARIEL J. MORRONE}

Doctor en Historia (Universidad de Buenos Aires) y Becario Posdoctoral (Consejo Nacional de Investigaciones Científicas y Tecnológicas). Directora: Dra. Ana María Presta. Programa de Historia de América Latina, Instituto de Historia Argentina y Americana “Dr. Emilio Ravignani”, Facultad de Filosofía y Letras, UBA, Argentina. Correo Electrónico: arielmorri@yahoo.com.ar 